\title{
O tratamento da concordância verbal no livro didático "Português: Linguagens": um estudo sociolinguístico e uma proposta de atividade ${ }^{i}$
}

\author{
Gabriella Cristina Vaz Camargo* \\ Simony Alves de Oliveira**
}

\begin{abstract}
Resumo: O objetivo deste trabalho foi refletir acerca do tratamento dado à concordância verbal a partir da perspectiva da sociolinguística. Para isso, buscamos entender como o fenômeno é apresentado nas gramáticas de Bechara (2009) e Perini (2010); depois, analisamos duas edições do livro didático "Português: Linguagens", de Cereja e Magalhães (2005; 2016) e, por último, propomos uma atividade, a partir do Poetry Slam, com base nos três eixos para o ensino de gramática de Vieira (2018). Os resultados evidenciaram a importância de proporcionar aos alunos uma reflexão sobre a concordância verbal em situações mais ou menos monitoradas.

Palavras-chave: Concordância verbal. Livro didático. Três eixos para o ensino de gramática.
\end{abstract}

\begin{abstract}
The aim of this work was to reflect on the treatment given to verbal agreement from the perspective of sociolinguistics. For this, we seek to understand how the phenomenon is presented in the grammars of Bechara (2009) and Perini (2010); then, we analyzed two editions of the textbook "Português: Linguagens", by Cereja and Magalhães (2005; 2016) and, finally, we propose an activity, based on the Poetry Slam, based on the three axes for teaching grammar by Vieira (2018). The results showed the importance of providing students with a reflection on verbal agreement in more or less monitored situations.
\end{abstract}

Keywords: Verbal agreement. Textbook. Three axes for teaching grammar.

Resumen: el objetivo de este trabajo fue reflexionar sobre el tratamiento de la concordancia verbal a partir de la perspectiva de la sociolingüística. Para ello, buscamos entender como el fenómeno es discutido en las gramáticas de Bechara (2009) y Perini (2010); en seguida, analizamos dos ediciones del manual didáctico "Português: Linguagens", de Cereja y Magalhães (2005; 2016) y, por último, proponemos una actividad, a partir del Poetry Slam, con basó en los

\footnotetext{
${ }^{\text {i }}$ Agradecemos à Profa. Dra. Rosane de Andrade Berlinck e à Profa. Dra. Juliana Bertucci Barbosa, que ministraram a disciplina "Seminários em Sociolinguística", do Programa de Pós-graduação em Linguística e Língua Portuguesa (PPGLLP), da Universidade Estadual Paulista (UNESP), Câmpus de Araraquara, pelas contribuições dadas a este trabalho.

* Doutoranda pelo Programa de Pós-Graduação em Linguística e Língua Portuguesa, da Universidade Estadual Paulista (UNESP), Câmpus de Araraquara. http://orcid.org/00oo-0002-2499-3460 / gabriellavazcamargo@gmail.com

${ }_{* *}^{*}$ Mestranda Programa de Pós-Graduação em Linguística e Língua Portuguesa, da Universidade Estadual Paulista (UNESP), Câmpus de Araraquara. http://orcid.org/0000-0002-3047-0201 / simonyoliveiralves2016@gmail.com
}

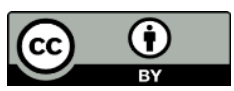

Este artigo está licenciado sob forma de uma licença Creative Commons Atribuição 4.0 Internacional, que permite uso irrestrito, distribuição e reprodução em qualquer meio, desde que a publicação original seja corretamente citada. 
tres ejes para la enseñanza de gramática de Vieira (2018). Los resultados evidenciaron la importancia de proporcionar a los alumnos una reflexión sobre la concordancia verbal en situaciones más o menos monitoreadas.

Palabras clave: Concordancia verbal. Manual didáctico. Tres ejes para la enseñanza de gramática.

\section{Considerações iniciais}

As postulações teóricas da sociolinguística buscam compreender a língua em uso em diferentes comunidades de fala com o objetivo de investigar seus aspectos linguísticos e sociais. O olhar lançado à língua, nesse domínio teórico, parte do pressuposto de que é social, heterogênea e instável, admitindo diversas variações. Dessa forma, o objeto de estudo da sociolinguística é a variação e a mudança linguística que, segundo Mollica (2003, p. 10), “constitui um fenômeno universal e pressupõe a existência de formas linguísticas alternativas denominadas variantes". Para compreender a variação é preciso considerar alguns fatores sociais, como a identidade social do falante, a identidade social do receptor, o contexto social e, ainda, as atitudes linguísticas (MOLLICA, 2003).

Labov (2008, p. 215) afirma que "a língua é uma forma de comportamento social, [...] ela é usada por seres humanos num contexto social, comunicando suas necessidades, ideias e emoções uns aos outros”. Podemos depreender que não se pode estudar a língua sem considerá-la em seu âmbito social e as formas de interação que os indivíduos efetuam por meio dela.

Destarte, este artigo aborda o tema da concordância verbal (doravante CV), em que analisamos sua abordagem gramatical, problematizamos seu tratamento no livro didático (doravante LD) e o prestígio social que é atribuído ao seu uso, em alguns casos que ocorreram na atualidade. Entendemos a CV, conforme Bagno (2009), como o fenômeno linguístico variável que mais provoca atitudes de discriminação, especialmente, entre os falantes urbanos letrados. A escolha por esse tema justifica-se 
pela possibilidade de reflexão sobre a gramática normativa, os recursos expressivos que possibilitam a compreensão de sentidos e a manifestação de normas/variedades, como propõe Vieira (2018). Com a finalidade de trazer contribuições ao ensino de Língua Portuguesa (doravante LP), a partir das discussões, propomos, ao final do artigo, uma atividade para o ensino do tema abordado.

Diante disso, este estudo tem dois objetivos centrais: o primeiro é compreender o tratamento dispensado à $\mathrm{CV}$ em gramáticas, no $\mathrm{LD}$ e na sociedade, especialmente quando relacionada ao prestígio social. E o segundo é propor uma atividade com base nos três eixos para o ensino de gramática propostos por Vieira (2018).

Para o cumprimento dos objetivos, o artigo está organizado em três partes principais: a primeira parte é destinada para (i) uma breve exposição sobre como o fenômeno da CV é apresentado nas gramáticas de Bechara (2009) e de Perini (2010); (ii) um exemplo de problematização do tema com foco no prestígio social, em que são consideradas situações cotidianas e (iii) uma apresentação de como os estudos sociolinguísticos têm buscado pensar o ensino de gramática na sala de aula.

Na segunda parte, é analisado o tratamento da CV no LD "Português: Linguagens" de Cereja e Magalhães, em que são comparadas duas edições, uma impressa e outra digital, a primeira, de 2005, e a segunda, de 2016. Já na terceira parte, são revisadas as discussões teóricas de Vieira (2018) sobre o ensino de gramática e, a partir disso, é proposta uma atividade para o ensino da CV a partir do gênero Poetry Slam. Esperamos que os debates levantados possam contribuir para pensarmos em um ensino de gramática normativa de forma contextualizada e de acordo com as realidades sociais e históricas dos alunos, de modo que lhes seja possível fazer reflexões acerca de seu uso.

\section{A título de contexto}




\subsection{O que é a concordância verbal?}

O tema da CV perpassa a vida escolar e é abordado nas gramáticas normativas e nos LD, tanto no Ensino Fundamental quanto no Médio. Esse fenômeno linguístico pode ser estudado sob diferentes perspectivas, que irão direcionar o trabalho realizado pelo professor na sala de aula. Para contextualizar e conceituar tal fenômeno, buscamos em duas gramáticas, de Bechara (2009) e de Perini (2010) ${ }^{1}$, para compreender qual o tratamento dado ao fenômeno.

Para Bechara (2009, p. 654, grifos do autor) “[...] em português a concordância consiste em se adaptar a palavra determinante ao gênero, número e pessoa da palavra determinada. [...] Diz-se concordância verbal a que se verifica em número e pessoa entre o sujeito (e às vezes o predicativo) e o verbo da oração”. Em seguida, o autor continua expondo as situações de uso mais complexo da CV, como, por exemplo, na situação em que é necessário adequar o verbo ao sujeito composto, anteposto e posposto. Ainda no capítulo sobre CV, Bechara afirma que:

Na língua oral, em que o fluxo do pensamento corre mais rápido que a
formulação e estruturação da oração, é muito comum enunciar primeiro o
verbo - elemento fulcral da atividade comunicativa - para depois se seguirem
os outros termos oracionais. Nestas circunstâncias, ofalante costuma enunciar
o verbo no singular, porque ainda não pensou no sujeito a quem atribuirá a
função predicativa contida no verbo; se o sujeito, neste momento, for pensado
como pluralidade, os casos de discordância serão aí frequentes. [...]. A língua
escrita, formalmente mais elaborada, tem meios de evitar estas discordâncias.
(BECHARA, 2009, p. 656 , grifos nossos).

Observamos que a discussão sobre a variação que ocorre em relação à CV é, de certa forma, considerada na gramática de Bechara (2009). Ao se referir à língua oral e ao considerar que primeiro o falante pensa no verbo singular e depois no sujeito, conforme

\footnotetext{
${ }^{1}$ O trabalho de Bechara (2009) se ocupa em analisar a língua escrita, e o trabalho de Perini (2010), a língua falada. Nosso objetivo não é desenvolver profundas comparações entre as duas gramáticas, mas compreender como o fenômeno da CV é conceituado e abordado nelas, especialmente, em relação à variação.
} 
destacamos acima na citação, o autor considera que é possível, especialmente em casos de sujeito posposto, a variação em relação à CV.

Em relação à gramática de Perini (2010), observamos que o autor não busca postular recomendações sobre algo que seja "certo ou errado" ou até mesmo "adequado ou inadequado", mas refletir sobre como se empregam as variedades linguísticas. Perini inicia seu capítulo sobre CV estabelecendo uma crítica às gramáticas tradicionais, que consideram que a concordância funciona "como uma espécie de harmonia entre o verbo e um dos termos da oração, o sujeito" (PERINI, 2010, p. 273, grifos do autor). Para o autor, é preciso reelaborar o conceito desse fenômeno, pois a CV é mais restrita no português falado no Brasil do que no português que é apenas escrito (considerando aqui também os outros países que possuem o português como língua materna). Em suas palavras:

Não só não se usam as formas ditas de "segunda pessoa (gramatical)", como vais ou ides, mas mesmo as formas de terceira pessoa do plural, vão e andam, tendem a perder espaço em favor das de terceira do singular vai e anda, frases como:

[1] Elas não consegue subir no banco.

São correntes na fala da maioria dos usuários do PB. Aqui vou descrever primariamente a forma mais conservadora, ou seja,

[2] Elas não conseguem subir no banco.

Mas é importante ter em mente que há muita variação nesse ponto.

(PERINI, 2010, p. 273).

Nos exemplos apresentados pelo autor, são destacados, primeiro, a variação dos falantes do português brasileiro (em que não há uma relação de concordância padrão entre o sujeito em terceira pessoa e o verbo) e segundo, a forma tradicional (ou conservadora) de se dizer a mesma frase e, por último, a reflexão que o autor propõe ao afirmar que existem muitas variações sobre esse assunto. Entendemos que, também, na gramática de Perini (2010), há o reconhecimento da variação da CV.

Nessa mesma página, o autor adicionou a seguinte nota de rodapé: "Mas todas as variedades do PB têm alguma concordância verbal, porque nenhuma aceita 'eu chegou' ou 'ela cheguei”' (PERINI, 2010, p. 273, grifos do autor). Portanto, observamos que o autor 
reconhece certa estrutura na língua portuguesa que obedece ao sentido, pois as variações obedecem a determinadas regras.

Temos, basicamente, dois objetivos gerais ao trazermos as gramáticas de Bechara (2009) e Perini (2010) para discussão: o primeiro é conceituar a CV, a compreendendo como responsável por estabelecer "concordância" ou "harmonia” entre o verbo e o sujeito; e o segundo é contextualizar seu uso e mostrar que, mesmo não sendo, muitas vezes, amplamente reconhecida na gramática normativa, a $\mathrm{CV}$ possui variações. É importante destacar que há tratamentos diferentes a depender da perspectiva que é analisada. Ressaltamos que existem outras gramáticas, como é o caso das pedagógicas², que têm como objetivo trazer contribuições para ensino de LP e que, obviamente, apresentam outros caminhos para se pensar a CV.

\subsection{Concordância verbal e algumas problematizações sociais}

O uso da CV é muito valorizado e está intimamente ligado ao prestígio social. Diversos são os casos de "erros" de CV apontados e criticados em sites de notícia, de fofoca, de conteúdos para o Exame Nacional do Ensino Médio (ENEM) e vestibulares, de dicas para entrevistas de emprego, entre outros tipos de plataformas digitais. Em geral, aquele que não faz um "bom" uso da CV é estigmatizado.

Em maio de 2011, o Programa Nacional do Livro Didático (PNLD) aprovou uma lista de livros didáticos que deveriam ser utilizados nas escolas e, entre eles, estava o livro "Por uma vida melhor" de Heloísa Ramos, destinado aos alunos da EJA (Educação de Jovens e Adultos). Tal aprovação causou polêmica, pois o capítulo denominado "Ler é diferente de falar", direciona o aluno a tratar das variedades linguísticas excluindo a noção de "certo/errado" e propondo a de "adequado/inadequado". Um dos exemplos que constitui o capítulo é: "nós pega o peixe" (RAMOS, 2011, p. 15); trata-se de uma oração

\footnotetext{
${ }^{2}$ Nos referimos, por exemplo, ao trabalho de Bagno (2012).
} 
que, de acordo com a gramática normativa, apresenta desacordo verbal, mas que é comum na fala dos brasileiros. Os exemplos foram muito criticados em diferentes sites de notícias e blogs ${ }^{3}$, os quais acusavam a autora de ensinar a LP de maneira "errada” aos alunos.

Outro exemplo sobre como o uso da CV é associado ao prestígio social é o caso da jornalista Maria Júlia Coutinho (também conhecida como Maju Coutinho). Além de lidar com o preconceito racial por ser negra, quando assumiu a apresentação de um jornal televisivo com considerado índice de audiência, em reconhecida emissora de TV e com transmissão aberta para todo o país, sofreu inúmeras críticas por, algumas vezes, não fazer o uso da CV de acordo com a gramática normativa em sua fala. Orações como “a maioria estão" e "as manchas de óleo continua” foram destacadas como "erros" da apresentadora.

Os dois exemplos que mostramos acima giram em torno do uso da CV e trazem à tona uma discussão sobre prestígio social. Um LD que é criticado e uma jornalista que é descredibilizada são situações em que o uso em acordo com a gramática normativa é mais prestigiado do que a compreensão no momento da comunicação. Entretanto, existem alguns usos da CV previstos nas gramáticas que podem favorecer a ausência da concordância, como o caso do sujeito posposto e da concordância ideológica.

Para compreender o caso do sujeito posposto, primeiro é preciso reconhecermos que na LP há a predominância de uma ordem, denominada ordem direta, ou seja, sujeito+verbo+objeto, porém, também é comum encontrarmos alguns termos em outras posições na oração. É justamente isso que se entende por ordem inversa ou invertida, na qual alguns termos são encontrados em combinação contrária ao esperado (ex.: verbo+sujeito = sujeito posposto), como, por exemplo, na oração: "Compareceram à reunião os alunos do Ensino Médio”.

\footnotetext{
${ }^{3}$ Alguns exemplos dessas matérias podem ser acessados por meio do infográfico: TERRA. Livro didático $e$ a polêmica. 2011. Disponível em: https://bit.ly/3mckQOm. Acesso em 14 ago. 2021.
} 
O segundo caso, chamado de concordância ideológica ou silepse, acontece quando o termo flexionado concorda com a ideia do contexto geral da frase e não segue critérios gramaticais. A concordância ideológica pode ser de pessoa, gênero e/ou número, como por exemplo: "O brasileiro é um povo persistente, não desistem nunca".

Observamos que em algumas situações o uso da CV, na LP, é desfavorecido, o que contribui para o desacordo. Entretanto, é preciso ressaltar que a concordância ideológica, por exemplo, é muito comum em textos literários, histórias em quadrinhos e letras de música, mas esses textos nem sempre são criticados ou descreditados.

Logo, concordamos com as reflexões de Bagno (2012) sobre as concordâncias, tanto verbal quanto nominal (apesar desta última não fazer parte dos enfoques deste trabalho), serem responsáveis por estigmatizar e "separar" os que falam "certo" e os que falam “errado”. E, para seguirmos para as próximas discussões deste artigo, retomamos suas palavras: "não existe ninguém que realize a concordância em todas as circunstâncias previstas pela gramática normativa, nem mesmo em textos escritos mais monitorados" (BAGNO, 2012, p. 641).

\section{O ensino da concordância verbal na visão dos estudos sociolinguísticos}

Os estudos na área de sociolinguística têm buscado promover uma discussão que incentive o ensino contextualizado e reflexivo de gramática normativa nas aulas de LP, em que sejam propostas atividades que considerem o uso da língua e suas variações de forma relacionada às questões histórico-sociais (CHAGAS, 2018).

Entendemos que o ensino da CV, em muitos casos, tem sido tratado a partir de um modelo de memorização de regras, que reflete protótipos ultrapassados de ensino, muitas vezes distantes da realidade até mesmo dos falantes mais escolarizados. A compreensão do enunciado deve ser mais importante do que a realização da CV de 
acordo com a norma-padrão e, para isso, é preciso (re)pensar o ensino de LP considerando que o contexto comunicativo é que determina qual a variedade que deve ser utilizada. Sobre o tema, Rissato (2018) esclarece:

\begin{abstract}
Para um falante nativo de língua portuguesa, dizer "Os meninos comeram" ou "Os meninos comeu", com ausência de concordância verbal, promoverá o mesmo significado, comprovando que a não realização da $\mathrm{CV}$ não pode ser considerada erro. Neste caso, o que ocorreu foi apenas uma inadequação à norma culta da língua. Os alunos precisam ser levados a compreender que determinados contextos, mais formais e monitorados, exigem que eles marquem a CV de acordo com a norma culta, como em uma entrevista de emprego ou em um vestibular. $\mathrm{O}$ ensino precisa, portanto, ser reflexivo e não impor uma variedade linguística simplesmente por questão de prestígio. (RISSATO, 2018, p. 148, grifos da autora).
\end{abstract}

Entendemos que o uso ou não da CV deve acontecer de maneira reflexiva, por isso, o ensino deve permitir que o aluno saiba distinguir os contextos que exigem uma maior monitoração e formalidade dos que não exigem. Assim, em uma situação de comunicação, irão saber quais variações são adequadas para o momento, sem imposições.

O uso da CV está relacionado, também, ao gênero textual. Por exemplo, os gêneros bilhete, ligação telefônica com algum familiar, mensagem instantânea para algum amigo, post pessoal no Facebook etc., são gêneros que não exigem alto grau de monitoração. Em contrapartida, outros gêneros como entrevista, redação de vestibular, artigo científico, conferência acadêmica, entre outros, ao contrário dos anteriores, exigem alto grau de monitoração. Dessa forma, o aluno deve reconhecer quais adequações são necessárias em sua fala e também em sua escrita considerando, também, o gênero. Esse reconhecimento deve ser espontâneo e desprovido de preconceitos.

De acordo com os estudos de Vieira e Brandão (2014), a gramática normativa concebe a língua como algo homogêneo. Por isso, o seu ensino é, constantemente, associado à noção de "certo" e "errado", o que acentua uma visão de que só há uma possibilidade na língua. Entretanto, as autoras discordam desse posicionamento e afirmam que "escrever bem" deveria ser associado a "escrever de maneira clara" e não, necessariamente, “escrever correto". Para Bortoni-Ricardo et al. (2014), a melhor 
maneira de se abordar a variação da CV dentro da sala de aula é relacionando-a aos diversos fatores que a influenciam, como o sujeito posposto e a concordância ideológica, comentados no tópico anterior deste artigo.

Diante do exposto, para seguirmos com as discussões sobre o tratamento da CV no LD, retomamos as reflexões de Chagas (2016) sobre o fato de que, apesar dos estudos linguísticos terem se desenvolvido a partir do século XX e contar com ampla divulgação dos pressupostos teóricos de Ferdinand Saussure (1857-1913), "ainda há muito a se fazer no campo do aproveitamento dos resultados científicos para o contexto pedagógico" (CHAGAS, 2016, p. 44).

\section{Observações sobre o tratamento da concordância verbal no LD "Português: Linguagens" de 2005 e 2016}

A partir das discussões levantadas acima, realizamos uma breve análise para compreender como se dá o tratamento da $\mathrm{CV}$ na $3^{\underline{a}}$ edição do LD para $3^{\underline{a}}$ série do Ensino Médio "Português: Linguagens" de Cereja e Magalhães, primeiro na versão de 2005, aprovada pelo PNLEM de 2009, 2010 e 2011 em que, para este trabalho, utilizamos a versão impressa, e depois a $11^{\text {a }}$ edição, de 2016 , uma versão atualizada em relação à anterior em que utilizamos a versão digital. Nosso objetivo foi observar as principais diferenças e semelhanças nessas duas versões, buscando entender se houve ou não alguma mudança no tratamento da CV. Abaixo, os livros didáticos analisados: 
Figura 1: Livro didático “Português: Linguagens” de 2005 e 2016

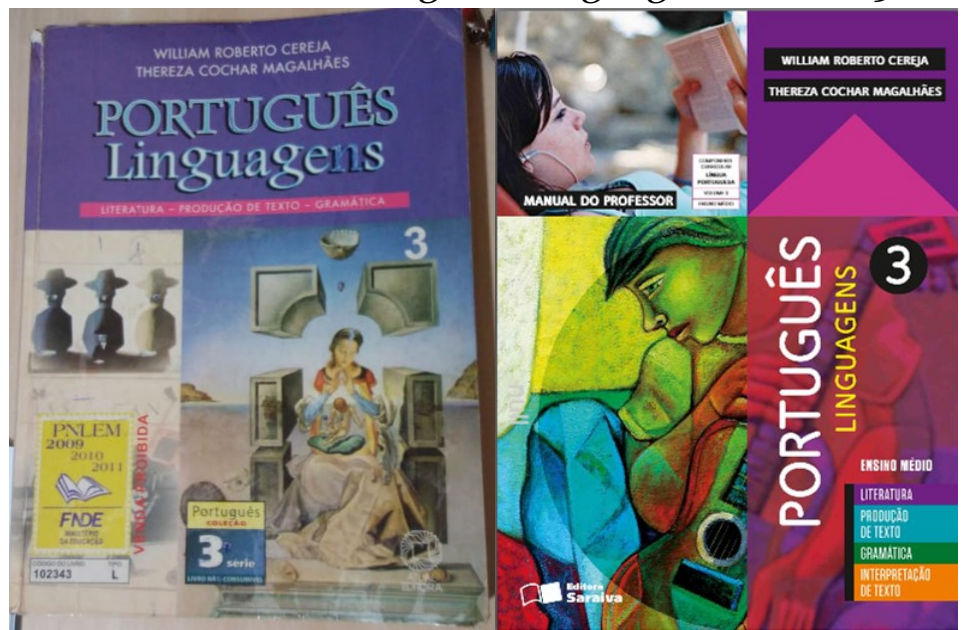

Fonte: Elaborado pelas autoras a partir de Cereja e Magalhães $(2005,2016)$

Algumas diferenças estão relacionadas à organização dos capítulos. A versão de 2005 conta com 4 unidades e 38 capítulos, que se subdividem em três grandes áreas: literatura, produção de texto e gramática. Já a versão de 2016 conta com 4 unidades e 36 capítulos, que são subdivididos em quatro grandes áreas: literatura, produção de texto, gramática e interpretação de texto. É importante destacar que, na versão de 2016, cada capítulo possui um tópico para discutir sobre o Exame Nacional do Ensino Médio (ENEM), o que em 2005 não era possível, já que a prova não era popular como hoje (tal popularidade já existia, também, em 2016). Apesar dessas diferenças voltadas para sua organização, ambas as versões possuem um capítulo intitulado "Concordância verbal” e que tem como objetivo estudar o fenômeno.

Em relação às semelhanças, observamos que as explicações gramaticais, nas duas versões, são as mesmas, ou seja, os trechos explicativos, os exemplos e a distribuição das informações foram conservados. Além disso, também observamos que os exercícios sobre CV sofreram poucas alterações significativas em suas propostas e também nas alternativas dispostas ${ }^{4}$.

\footnotetext{
${ }^{4}$ Por questões de delimitação de páginas, optamos por apenas descrever as semelhanças e diferenças entre as versões dos LD em análise. Apenas trouxemos, como exemplo, exercícios que constituem as seções
} 
Contudo, apesar dessas semelhanças, as últimas seções dos capítulos, intitulados "Semântica e interação", na versão de 2005, e "Semântica e discurso", na versão de 2016, apresentaram diferenças em relação à utilização de termos como "variedade padrão" e "norma-padrão". A versão de 2005 possui um número considerável do termo "variedade padrão" na maioria dos enunciados dos exercícios e, na versão de 2016, esse termo é substituído por "norma-padrão". Podemos inferir que, enquanto "variedade padrão" remete à ideia de língua heterogênea visto que, apesar de se referir a um certo padrão, centra a discussão na questão da variedade. Já "norma-padrão" remete ao oposto, à ideia de língua homogênea, centrando a discussão na questão da norma e também se voltando àquilo que se entende como padrão.

No entanto, conforme veremos, é na versão de 2016 que as atividades apresentadas contemplam mais a variação, o que se torna, nesse sentido, uma questão problemática, visto que a versão que mais utiliza o termo variação vem a ser, justamente, a que menos contempla tal discussão, enquanto a versão que mais o faz, usa um termo não correspondente que é "norma-padrão". Essa problemática reforça a discussão feita por Faraco e Zilles (2017) acerca de questões relacionadas à norma e ensino, em que os autores apontam que o conceito de norma possui confusões terminológicas, as quais também fizeram parte das reflexões de Bagno (2017) e Faraco (2008). Apesar de os nossos objetivos não se centrarem nessa discussão, a colocamos em pauta porque tais confusões podem ser vistas no que diz respeito ao LD em questão, dada a problemática exposta.

Observamos também que na versão de 2005, no capítulo analisado, não havia muitos exercícios que refletissem sobre a linguagem coloquial, os que apareciam utilizavam os termos "língua de forma coloquial" ou "linguagem falada". Na versão de 2016, constatamos que havia um número maior de exercícios que buscavam abordar a linguagem coloquial e o uso da CV de uma forma mais reflexiva. Trouxemos um exemplo abaixo:

\footnotetext{
"Semântica e interação" (2005) e "Semântica e discurso" (2016) para observar como o LD propõe a reflexão sobre os usos da língua, já que nos importa, também, entender as formas de seu ensino e de sua reflexão.
} 
Figura 2: Atividade sobre "linguagem falada", versão de 2005

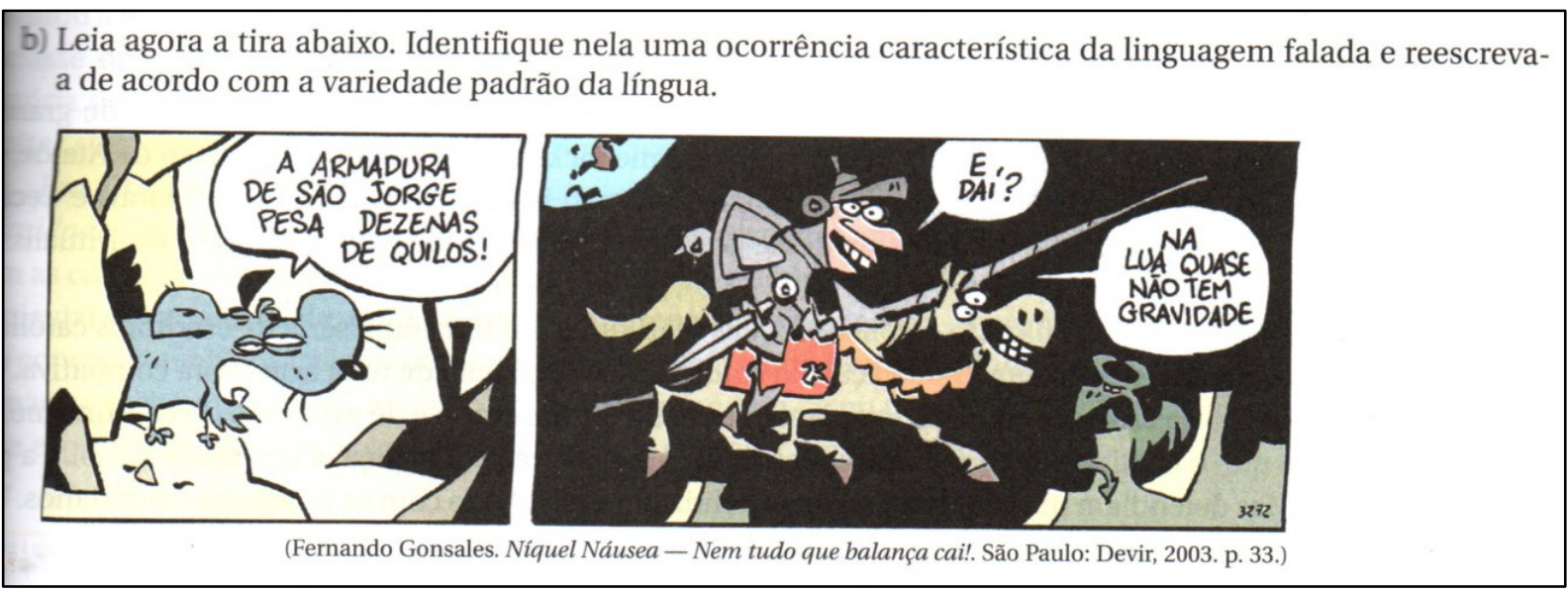

Fonte: Cereja e Magalhães (2005)

Na figura 2 (acima), na versão do LD de 2005, um exercício do capítulo que compõe a seção "Semântica e interação" pede para que o aluno leia a tirinha, identifique nela uma ocorrência comum na "linguagem falada", e que a reescreva utilizando a “variedade padrão da língua”. Nesse exercício, a ocorrência em questão, é o uso do verbo "ter" ao invés de "haver". Essa troca é comum na fala e acontece no último quadrinho, quando o personagem afirma: "Na lua quase não tem gravidade". Essa atividade não propõe uma reflexão sobre $\mathrm{CV}$, mas a destacamos, porque solicita ao aluno que coloque em acordo com a "variedade padrão", o que não está em acordo.

Na versão de 2016, o exercício que constitui a seção "Semântica e discurso"-propõe que o aluno leia o poema de Patativa do Assaré5 e responda às questões. Dentre elas, observamos que, neste caso, há uma preocupação maior em se refletir sobre as escolhas e os usos do autor. Observe abaixo:

\footnotetext{
${ }^{5}$ Patativa do Assaré (1909-2002) foi poeta popular, compositor e cantor nordestino. Seu trabalho recebeu inúmeros reconhecimentos e em sua literatura eram valorizados os aspectos linguísticos coloquiais e regionais. Dentre os temas que abordava, críticas relacionadas ao descaso dos governantes em relação à seca do sertão eram frequentes.
}

\section{Revista Investigações, Recife, v. 34, n. 2, p. 1 - 31, 2021 ISSN Digital 2175-294x}


Figura 3: Atividade sobre concordância, versão de 2016

\title{
SEMANTICA E DISCURSO
}

\author{
Leia este poema, de Patativa do Assaré:
}
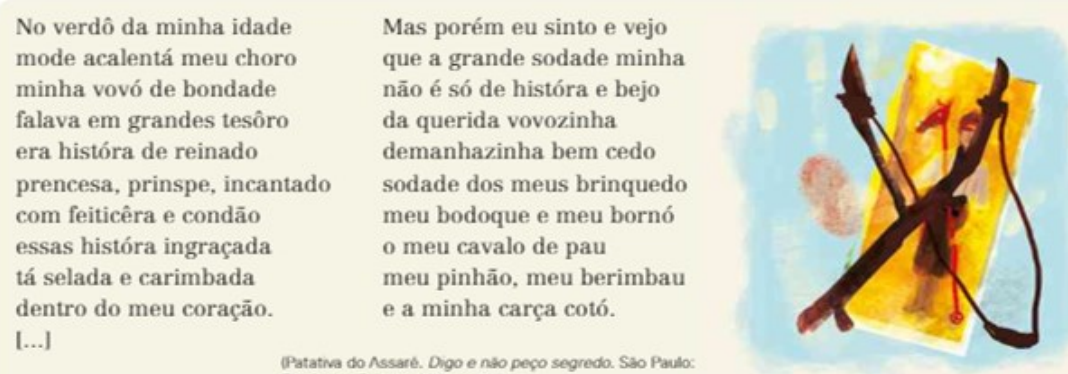

2. Releia os versos e observe as concordâncias nominal e verbal:

"essas históra ingraçada / tá selada e carimbada / dentro do meu coração."

a) Como ficariam esses versos se fossem reescritos de acordo com a norma-padrão?

b) Observe que, nesses versos, apenas o pronome essas está no plural. Levante hipóteses: Em termos de comunicação, é necessário que todas as palavras dessa expressão estejam no plural? Por quê? Năo, colocando-se o primeiro termo - pronome - no plural, jă se deduz que săo vacrias histórias, enăo apenas ume

c) Levante hipóteses: Por que ocorre esse fenômeno na fala? Ocame a supressăo do plural por economia linguistica

Fonte: Cereja e Magalhães (2016)

A questão 2, apresentada na figura 3 (acima), direciona o aluno a refletir sobre a variedade da concordância, trazendo para debate os trechos: "essas história ingraçada / tá selada e carimbada / dentro do meu coração", com as seguintes perguntas: "a) Como ficariam esses versos se fossem reescritos de acordo com a norma-padrão?”, “b) Observe que, nesses versos, apenas o pronome essas está no plural. Levante hipóteses: em termos de comunicação, é necessário que todas as palavras dessa expressão estejam no plural? Por quê?” e “c) Levante hipóteses: Por que ocorre esse fenômeno na fala?”.

Observamos que a versão de 2016 procura proporcionar aos alunos reflexões sobre o uso da concordância, nesse caso, refere-se à concordância verbal e também nominal, mostrando, inclusive, trechos do poema em que não há a realização dessa concordância. Entendemos que ainda existem muitas questões relacionadas ao ensino da CV que 
precisam ser revistas e repensadas (como a questão terminológica, por exemplo), porém, consideramos positivos alguns avanços, como esse último exercício mostrado.

A partir da breve observação realizada, entendemos que o LD "Português: Linguagens", de 2016, em relação à versão de 2005, apresenta algumas adaptações em relação à terminologia e também novas propostas para refletir sobre o uso da CV. Entretanto, não observamos uma questão que discutisse a respeito do prestígio social atribuído à concordância ou sobre maneiras de se combater o preconceito linguístico em relação aos falantes que são estigmatizados. Assim, apesar dos avanços em relação ao reconhecimento da variação, não há uma proposta para desmistificar o seu uso. No próximo tópico, iremos discutir sobre os três eixos para o ensino de gramática, propostos por Vieira (2018) e, posteriormente, apresentaremos uma proposta de atividade comentada.

\section{Três eixos para o ensino de gramática}

Ainda no que tange ao referencial teórico, além daquilo que diz respeito especificamente ao tema da CV, utilizamos também a proposta de Vieira (2018) sobre os "três eixos de aplicação do ensino de gramática nas aulas de Língua Portuguesa” (VIEIRA, 2018, p. 52). Tal proposta é parte do que consideramos como referencial teórico por acreditarmos, de fato, em um ensino de gramática a partir desses três eixos. A autora parte das orientações oficiais para o ensino de gramática, apresenta a proposta com base em uma literatura que também reflete acerca desse ensino e, posteriormente, detalha o que propõe em cada eixo.

Neste trabalho, perpassamos por cada eixo por ser essa a proposta que embasa a nossa (que virá a ser apresentada). Ressaltamos, contudo, que os trabalhos de Chagas 
$(2016 ; 2018)$ são, também, basilares para este trabalho já que a autora se utiliza da mesma proposta de Vieira para refletir acerca do tema da CV.

O primeiro deles - Eixo 1 - sinteticamente se trata da "sistematicidade" da língua de modo reflexivo. Para tanto, Vieira (2018) reflete, com base em outro teórico, Franchi (2006), a respeito das naturezas das atividades escolares voltadas para o conteúdo gramatical, sendo elas: a linguística, a epilinguística e a metalinguística. A natureza linguística diz respeito, basicamente, à produção e à compreensão de textos; trata-se do exercício do "saber linguístico", uma tentativa de "tornar operacional e ativo um sistema a que o aluno já teve acesso fora da escola, em suas atividades linguísticas comuns" (FRANCHI, 2006 apud VIEIRA, 2018, p. 52).

A natureza epilinguística objetiva que o aluno "opere" (para usar os mesmos termos de Franchi) sobre a própria linguagem. Se na natureza linguística espera-se tornar operacional o sistema linguístico a que o aluno já teve acesso fora da escola, na epilinguística espera-se que o aluno "brinque" com essa linguagem, podendo, inclusive, transformá-la. Quanto à natureza metalinguística, considerando que o aluno já tenha tornado operacional o sistema linguístico apreendido fora da escola e já esteja operando tal sistema, inclusive após comparar, transformar, experimentar e investir nele, esperase que o aluno o sistematize através de um trabalho inteligente e consciente (VIEIRA, 2018).

O Eixo 1, como exposto, está intimamente ligado às questões operacionais da linguagem do aluno, ou seja, à sistematização. O trabalho com a gramática através desse eixo possibilita que o aluno seja levado a refletir acerca da própria linguagem e tome consciência dela, e é por esse motivo que a autora o considera transversal aos outros eixos. O Eixo 1, portanto, se trata de ensino de gramática e atividade reflexiva. $\mathrm{O}$ trabalho com a CV relaciona-se a esse eixo por objetivar-se que o aluno tenha consciência linguística sobre esse fenômeno e saiba operá-lo, considerando "a atividade do falante que não é neutra diante dos eventos que vai descrever" (FRANCHI, 2006 apud CHAGAS, 2016, p. 65). 
O Eixo 2 relaciona-se ao ensino de gramática e à produção de sentido e, para tanto, a autora se utiliza de correntes científicas que demonstram a relação entre ambos para apresentar considerações a respeito desse eixo. Dentre essas correntes, duas delas são selecionadas: a interpretação funcionalista da gramática e a Análise Semiolinguística do Discurso, das quais, segundo Vieira (2018), Neves (2006 apud VIEIRA, 2018) ${ }^{6}$ é a principal representante da primeira e Pauliukonis (2007 apud VIEIRA, 2018) ${ }^{7}$ bem sintetiza a segunda. A relação proposta nesse segundo eixo pode aparecer no texto tanto com um sentido local quanto com um sentido mais amplo, ou seja, o Eixo 2 pode se dar no plano textual e/ou no discursivo. O fenômeno da CV se dá, primeiramente, no plano textual, por se tratar de um fenômeno linguístico, mas isso não significa que ele não apareça no plano discursivo.

Chagas (2018) pontua que fazer ou não a CV de acordo com o uso padrão, a depender do contexto e do gênero textual em questão, pode se tratar de uma estratégia por parte do aluno que, ao tomar consciência do que está fazendo, atribui sentido ao uso (ou ao não uso) desse fenômeno linguístico. Desse modo, vemos o aluno mobilizando tanto o Eixo 1 quanto o Eixo 2 já que ele reflete sobre a língua e, a partir dessa reflexão, dá sentido ao texto que está produzindo, além de ampliar seu repertório linguístico.

Considerando o trabalho didático com o Eixo 2, sua importância se dá na necessidade de relacionar a reflexão acerca da língua ao uso da mesma, objetivando que se pense também na situação comunicativa. Ao pensar em tal situação, o aluno dá sentido ao conteúdo estudado. Para tanto, os gêneros textuais vêm à baila porque é através deles que se tem a materialização do uso da gramática e, consequentemente, da CV. Desse modo, tal fenômeno é um recurso expressivo utilizado para dar sentido ao texto.

\footnotetext{
${ }^{6}$ NEVES, M. H. M. Texto e gramática. São Paulo: Contexto, 2006.

7 PAULIUKONIS, M. A. L. Texto e contexto. In: VIEIRA, S. R.; BRANDÃO, S. F. (Orgs.) Ensino de gramática: descrição e uso. São Paulo: Contexto, 2007. p. 237-258
} 
Ao pensarmos na situação comunicativa, somos levados para além da reflexão linguística e do sentido dado ao texto, chegando ao tópico da variação linguística, central para o trabalho com o Eixo 3. Esse terceiro eixo, denominado por Vieira (2018) como "Ensino de gramática, variação e normas", reflete acerca da heterogeneidade linguística e das normas que, muitas vezes, "ditam" qual delas deve ser utilizada pelos falantes nas mais variadas situações comunicativas ${ }^{8}$.

As escolhas feitas pelos falantes nem sempre se dão de forma consciente e muitas vezes eles fazem uso da variedade a que têm acesso em seu contexto, o que leva à estigmatização e ao preconceito linguístico. Esses problemas têm sido muito estudados pela área da sociolinguística por se tratar de uma relação direta entre a língua e a sociedade, mais especificamente, a estigmatização sofrida pelos falantes por parte de outros falantes ditos cultos. Görski e Freitag (2013) dirão que tal preconceito não diz respeito apenas ao âmbito linguístico, mas se esconde por trás de um preconceito social.

Trabalhar com o Eixo 3 é fundamental para as aulas de LP e para que os Eixos 1 e 2 sejam mobilizados eficientemente. Isso porque o Eixo 3 observa o funcionamento social da língua e reflete acerca das estruturas morfossintáticas utilizadas em contextos menos monitorados (nos referimos aqui aos trabalhos de Bortoni-Ricardo (2004; 2005) e as relacionam às estruturas que fazem parte da norma gramatical. Esse eixo objetiva propiciar ao aluno acesso às outras variedades, como, principalmente, a variedade de prestígio. Desse modo, é necessário valorizar o ensino não só da norma-padrão - para que tomem ciência de tal e não para impor sobre eles um padrão que, como aponta Faraco (2008), estimula um processo de uniformização, visto que esta não se trata de uma variedade mas, sim, "um construto sócio-histórico" (FARACO, 20o8, p. 75) que serve de referência para estimular tal processo - e/ou da gramatical, mas também da

\footnotetext{
${ }^{8}$ Por uma questão de espaço, não nos ocuparemos, no presente artigo, em falar sobre os conceitos de norma, mas sugerimos, para tanto, o trabalho de Faraco e Zilles (2017).
} 
norma culta9 , de fato utilizada pelos falantes, o que proporciona a eles um ensino de gramática fundamentado em padrões reais, como aponta Vieira (2018).

Chagas (2018), com base em Lucchesi (2015 apud CHAGAS, 2018) ${ }^{10}$, afirma que o acesso por parte do aluno não só às normas dominadas por ele, mas também às que ele não domina, é uma questão de cidadania, já que dominá-las faz com que ele seja capaz, caso queira, de transitar nos mais variados contextos e faça uso dos mais variados gêneros, sejam eles mais ou menos monitorados, o que também faz parte de um projeto de combate ao preconceito linguístico apresentado anteriormente.

\section{As atividades propostas}

Como exposto inicialmente, o presente artigo também objetiva apresentar uma proposta de atividade que se baseia tanto nas explicações e atividades presentes no LD "Português Linguagens" (2005; 2016) de Cereja e Magalhães, quanto na proposta dos três eixos de Vieira (2018), apresentada na seção anterior. Nossa proposta tem como foco o trabalho com o tema da CV, o qual sugerimos que seja apresentado e discutido antes da execução da atividade que propomos, a partir do tratamento dado ao tema nas versões do LD em questão e de gramáticas como as que apresentamos anteriormente. A atividade proposta neste trabalho visa aprofundar as discussões acerca da $C V$, e não dar

\footnotetext{
${ }^{9}$ Aqui entendemos tanto a norma-padrão quanto a norma culta com base nas discussões de Faraco (2008) e Faraco e Zilles (2017). Segundo Faraco (2008, p. 75, grifo do autor), "Se a norma culta/comum/standard é a variedade que os letrados usam correntemente em suas práticas mais monitoradas de fala e escrita, a norma-padrão não é propriamente uma variedade da língua, mas - como bem destaca Bagno (2007a) um construto sócio-histórico que serve de referência para estimular um processo de uniformização, enquanto que a norma gramatical é o nome pelo qual o autor chama a flexibilização, por parte de gramáticos da segunda metade do século XX, dos juízos normativos advindos dos movimentos de padronização linguística do século XIX."

${ }^{10}$ LUCCHESI, D. Língua e sociedade partidas: a polarização sociolinguística no Brasil. São Paulo: Contexto, 2015 .
} 
início a elas em sala de aula, como expomos no apêndice presente no fim deste texto. Desse modo, o trabalho com o tema da CV em sala de aula antes da aplicação da atividade é importante para que esta se realize efetivamente.

Para alcançarmos o objetivo de trabalhar com o fenômeno da CV, nos utilizamos de um gênero atual que se aproxima da linguagem do aluno já que se manifesta através da fala - portanto, mais oral, se considerarmos o contínuo de oralidade e letramento de Bortoni-Ricardo (2004) - em contextos menos monitorados - se considerarmos o contínuo de monitoração estilística. O gênero em questão é o Poetry Slam.

Assim como Chagas (2018) que, ao propor uma atividade, não pretendeu postular um padrão único e nem priorizar o padrão mais aceito socialmente, também não temos esse objetivo. Priorizamos que o aluno tenha acesso a todas as variedades e lance mão, conscientemente, da que considerar apropriada para o contexto em que estiver. Como dito anteriormente, julgamos importante que os alunos saibam que há um padrão, mas que não é comum que ele seja utilizado pelos falantes em situações menos monitoradas, ou seja, a língua falada por eles não é "errada”, apenas será considerada inadequada a depender da situação comunicativa.

A título de organização, propomos a presente seção da seguinte maneira: primeiro, uma breve contextualização acerca do Poetry Slam. Em seguida, o porquê de escolhermos tal gênero e tal poema para a atividade em questão e a disposição da atividade no artigo (apresentando, primeiramente, o texto base para responder às questões e, depois, cada questão seguida da justificativa que lhe cabe). Ao fim do artigo, como apêndice, há o produto contendo o plano de aula, que sintetiza a ideia exposta no corpo do artigo.

Seguindo a ordem planejada para apresentação das ideias, Poetry Slam é um movimento poético que teve início em Chicago, com Marc Smith, na década de 1980. Diz respeito às batalhas de poesias faladas nas quais os poetas devem declamar, performaticamente, poesias autorais em no máximo três minutos e sem acompanhamento musical, uso de figurinos ou elementos cinematográficos. Os poetas 
são avaliados por jurados escolhidos em meio à plateia e o que obtiver maior pontuação é o vencedor da batalha. Esse tipo de poesia chegou ao Brasil por volta de 2008 através da figura de Roberta Estrela D'Alva.

Escolhemos o Slam como central para a elaboração da nossa atividade por se tratar de um gênero que se aproxima da linguagem do aluno e que, possivelmente, o deixará confortável para refletir acerca da língua, mais especificamente, da norma gramatical. Essa preocupação existe porque é comum que os alunos não se interessem por questões gramaticais justamente por acreditarem que não "sabem" LP. Professores que não lançam mão da sociolinguística para ensinar LP podem, inclusive, considerar que alunos que sabem a língua são os que sabem fazer a $\mathrm{CV}$ com base em normas gramaticais, por exemplo, o que não só aponta para o prestígio de tal fenômeno, como também se trata de preconceito linguístico.

O poema escolhido, "Menimelimetros"11, da poeta Luz Ribeiro, reflete acerca do prestígio social de pesquisadores que têm a periferia e tudo o que faz parte dela como objeto de pesquisa, mas não têm um projeto que objetive mudar a realidade daqueles que nela habitam. "Os menino" a quem a poeta se refere são aqueles que moram na periferia e sofrem com a desigualdade social existente na nossa sociedade. Essa desigualdade, segundo ela, também é vista quando os pesquisadores precisam adentrar a periferia para estudá-la. A poeta, em alguns versos, faz o uso da CV de acordo com a norma gramatical e, em outros, não, o que nos leva a pensar que tais escolhas se dão de modo consciente. Essa questão da concordância foi crucial para a escolha do poema ${ }^{12}$.

\footnotetext{
${ }^{11}$ Vale ressaltar que os poemas recitados em batalhas de Poetry Slam são transcritos e expostos escritos apenas quando o (a) poeta publica-os em livros, caso contrário, por se tratar de um gênero oral, eles não possuem transcrições. Neste artigo, utilizamos uma transcrição feita por nós com base em um vídeo postado na plataforma do YouTube em 8 de agosto de 2016 por "Sociedade dos Poetas Subversivos". O vídeo, no entanto, que estava disponível através do link <https://www.youtube.com/watch?v=wcli4MWcYg>, atualmente não está mais disponível para acesso (isso pode acontecer por vários motivos, dentre eles: ou alguém pode ter denunciado o vídeo e a plataforma excluiu, ou a própria pessoa/página que postou pode ter excluído).

${ }^{12}$ Além das questões relacionadas à CV, o poema possibilita também uma reflexão acerca da concordância nominal, que pode ser percebido nos primeiros versos, "os menino", e no decorrer do poema (mesmo que, em sua maioria, através dessa mesma forma). O que se percebe, na verdade, é a não concordância nominal,
} 
$\mathrm{Na}$ primeira pergunta, solicitamos que os alunos assistam ao vídeo do poema antes de lerem a transcrição. Isso porque, como se trata de um gênero oral, acreditamos que para o aluno conseguir compreender o gênero ele precisa minimamente ter acesso a ele (mesmo que por meio de vídeos). Sendo o poema a base para a nossa atividade e a CV o tema a ser trabalhado, sugerimos apresentar, primeiro, o vídeo, em seguida, o poema transcrito por nós, e depois cada pergunta seguida por uma justificativa. Na justificativa de cada pergunta, apresentamos também qual eixo acreditamos estar sendo mobilizado.

É necessário pontuar que sugerimos que antes de iniciar a apresentação da atividade para os alunos, o plano de aula ${ }^{13}$ propõe que haja uma explicação acerca do Slam por se tratar de um gênero novo e que ainda não faz parte do currículo do ensino básico. Ademais, espera-se que o professor amplie a discussão a respeito do tema da CV e leve o aluno a refletir acerca do uso da língua a depender do contexto (seja ele mais ou menos monitorado). Assim, ao iniciar a atividade, o aluno já estará mais familiarizado tanto com o gênero quanto com o tema. Segue o poema base para as questões que aparecem subsequentes a ele.

\section{MENIMELIMETROS - Luz Ribeiro}

Os minino passam liso pelos becos e vielas os minino passam liso

Pelos becos e vielas Os mino passam liso

Pelos becos e vielas

vocês que falam becos e vielas

sabe (em?) quantos centímetros cabe um minino?

sabe de quantos metros ele despenca quando uma bala perdida o encontra?

sabe quantos nãos ele já perdeu a conta? quando cêis citam quebrada nos seus tcc's e teses cêis citam as cores da parede natural tijolo baiano? cêis citam os seis filhos que dormem juntos? cêis citam que o geladinho é bom só por que custa um real?

cêis citam que quando vocês chegam pra fazer suas pesquisas seus vidros não se abaixam? não citam, não escutam só falam, falácias!

é que cêis gostam memo é do gourmet da quebradinha

assim como acontece com a CV. No entanto, cientes de que tal fenômeno da concordância nominal poderia ser explorado na atividade proposta e de que tal discussão é possível, ressaltamos que esse não é o nosso objetivo visto que estamos refletindo e propondo, especificamente, a respeito da CV. Sendo assim, não vamos nos atentar às questões que tangem à concordância nominal.

${ }^{13} \mathrm{O}$ plano de aula se encontra como apêndice ao final do artigo. 
um sarau, um sambinha, uma coxinha mas entrar na casa dos minino que sofreram abuso durante o dia não cabe nas suas linhas suas laudas não comportam o batuque dos peitos laje vista pro córrego

seu corretor corrige as estruturas dos maderites quando eu me estreito no beco feito pros mininos ' $\mathrm{p}$ '

de (in)próprio

eu me perco

e peco por não saber nada

por não ser geógrafa

invejo tanto esses minino mapa

percebe, esses minino desfilam moda

havaianas número 35 / 40 e todos

que é tamanho exato pro seu pé número 38

esses minino tudo sem educação

que dão bom dia,

abrem até portão

tão tudo fora das grades escolares

nunca tiveram nada de ninguém

mas reforça a força, a tática

do tráfico

mais um refém

esses minino que num sabem nem escrever

marca os beco tudo

com caquinho de tijolo

pcc! Você vê. Vê? Vê?

num vê!

Que esses minino sem carinho

Não tem carrinho no barbante

pensa comigo que bonito

se fosse peixinho fora d'agua

a despencar no céu

mas é réu na favela

lhe fizeram pensar vôos altos

voa, voa, voa aviãzinho

E os minino corre, corre, corre

faz seus corre, corre, corre ...

podia ser adaga, flexa, lança

mas é lançado pra fora

vive pela margem

na quebrada do minino num tem nem ônibus

pro centro da capital

isso me parece um sinal

é tipo uma demarcação de até onde ele pode chegar

e os minino malandrão faz toda a lição

acorda cedo, dorme tarde

é chamado de função

queria casa

mas é fundação.

tem prestigio, não tem respeito

é sempre o suspeito de qualquer situação

cêis já pararam pra ouvir alguma vez o sonho dos minino?

é tudo coisa de centímetros

um pirulito

um picolé

um pai uma mãe

um chinelo que lhe caiba no pé

Um aviso:

quanto mais retinto o minino

mais fácil de ser extinto

seus centímetros

não suportam 9 milímetros

porque esses mininos

sentem metros

Disponível

em:

<https://www.youtube.com/watch? $\mathrm{v}=$ wcli44M-

$\underline{W c Y g}>$. Acesso em 29 de novembro de 2018.

\section{Questão 1:}

Assista ao vídeo do poema "Menimelimetros", da poeta Luz Ribeiro, e se atente às marcações de concordâncias verbais feitas (ou não) no poema.

Justificativa: A questão 1 mobiliza os três eixos. Se trata, primeiramente, de uma questão de natureza linguística já que se espera que o aluno veja o vídeo do poema e reflita acerca dele para se atentar às concordâncias verbais feitas ou não no texto. Ao se atentar às concordâncias verbais no poema, considerando que o aluno já tenha tido acesso ao gênero, ao tema da CV e aos mais variados contextos de 
produção de textos orais e escritos, como exposto no início desta seção, o aluno começará a entender o porquê de esse gênero especificamente, dado o contexto de produção, em sua maioria, não fazer a CV de acordo com a norma-padrão. Tal atitude por parte do aluno se trata da mobilização tanto do Eixo 1, em que ele reflete sobre a língua, quanto do Eixo 2, em que ele começa a dar sentido ao uso da CV no texto. Além disso, o aluno se familiarizará com a relação entre o tema gramatical proposto e as questões de variação linguística, o que sugere a mobilização do terceiro eixo.

\section{Questão 2:}

O vídeo é de um poema recitado em batalha de Poetry Slam. Você concorda com os momentos em que a poeta não concorda o verbo com o sujeito? Por quê?

Justificativa: Na segunda questão, acreditamos que, novamente, os três eixos sejam mobilizados. O primeiro eixo aparece através da natureza linguística já que se espera que o aluno busque compreender o texto, além de lançar mão da produção textual para respondê-la. A natureza epilinguística também surge no momento em que o aluno não só reflete sobre a linguagem, como também opera sobre ela concordando ou não com o modo como a CV se deu no poema. O Eixo 2 é mobilizado porque o aluno busca dar sentido ao conteúdo que aprendeu a respeito do tema a partir do momento que reflete acerca da situação comunicativa. E o Eixo 3 aparece porque o aluno é levado a refletir sobre a heterogeneidade linguística já que, mesmo que a não marcação da concordância não esteja de acordo com determinada norma, ela é feita no poema.

\section{Questão 3:}

Leia o poema transcrito pela professora e localize os verbos e os casos em que há ou não a concordância deles com os sujeitos. Por que você acha que em alguns momentos do poema há a marcação da concordância e em outros não?

Justificativa: A questão 3 pede que os alunos leiam o poema e façam um texto escrito para respondê-la e, só por isso, já mobiliza o Eixo 1 e sua natureza linguística. Ao localizar e comparar os versos, o aluno lança mão da natureza epilinguística já que opera sobre a linguagem. Os alunos também precisam refletir sobre a língua com base no que aprenderam acerca do tema (o que também faz parte da natureza linguística) e, já no que tange ao segundo eixo, precisam refletir acerca da produção de sentido, ou seja, são levados a pensar qual o objetivo da poeta ao fazer a concordância apenas em alguns momentos e em outros não. Essa escolha consciente da poeta, por se tratar, ao nosso ver, de um projeto de dizer específico no qual ela busca mostrar que, mesmo estando em um contexto menos monitorado, é capaz de fazer uso das regras de CV seja de acordo ou não com as normas gramaticais, faz com que os alunos mobilizem, também, o Eixo 3 já que refletem acerca das variações da língua e das normas de uso dela.

\section{Questão 4:}

Leia novamente o trecho a seguir do poema de Luz Ribeiro e responda às questões abaixo: 
"E os minino corre, corre

Faz seus corre, corre, corre

Podia ser adaga, flecha, lança

Mas é lançado pra fora

Vive pela margem”

a) O verbo "correr" não concorda com o sujeito no verso em que se apresenta. Você acredita que seja uma estratégia da poeta?

b) Você conhece o duplo sentido da palavra “corre” apresentada no texto?

c) A palavra "corre" está relacionada a outro trecho do texto? Qual?

Justificativa: A quarta questão apresenta natureza linguística já que demanda a leitura do aluno em função do gênero abordado e epilinguística ao criar condição para que o aluno analise aspectos constitutivos do gênero. De um modo geral, essa questão mobiliza os três eixos, porque leva a uma reflexão por parte dos alunos acerca da concordância verbal de acordo com a norma-padrão, a um acionamento do conhecimento de mundo deles para entender o duplo sentido do termo, e uma reflexão pautada na variação linguística a partir de seus próprios usos.

\section{Questão 5:}

O gênero poema é considerado um gênero mais monitorado no que tange à linguagem utilizada. Nesse caso, você considera que se trata de um poema em que a poeta monitorou a sua linguagem ou não? Há uma estratégia por parte da poeta por ter agido dessa forma?

Justificativa: Para responder essa questão, acreditamos que o aluno mobilize os três eixos. O primeiro porque é levado a refletir acerca da prática linguística em função de um projeto comunicativo. $\mathrm{O}$ Eixo 2 porque dá sentido às estratégias utilizadas pela poeta para fazer ou não a concordância. E o terceiro eixo porque o aluno pensa a respeito da variação como estratégia linguística.

\section{Questão 6:}

Leia a notícia a seguir e responda à questão subsequente. 
Figura 4: Matéria sobre a apresentadora Maria Júlia Coutinho no site da UOL

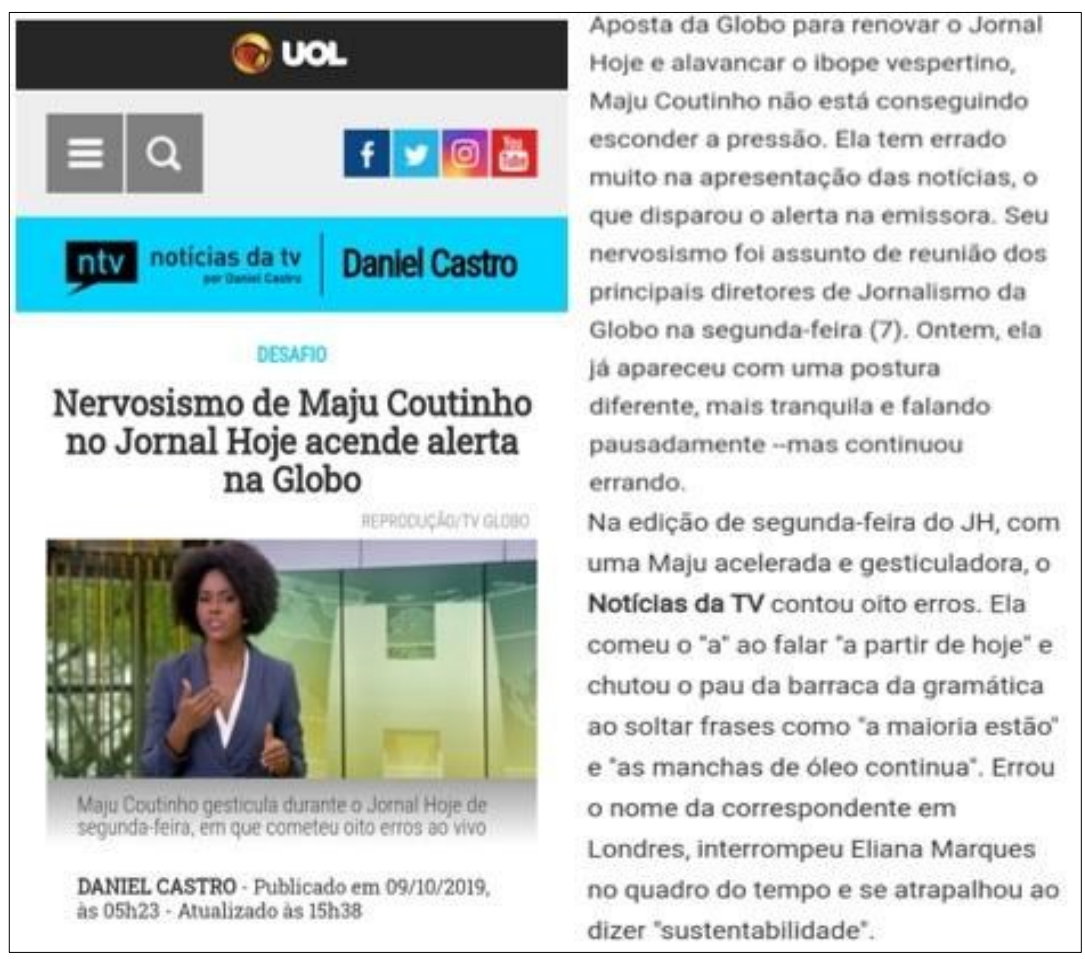

Fonte: https://bit.ly/3soaGLD. Acesso em: o8 ago. 2020

Apesar de a apresentação de um jornal ser um gênero mais monitorado e que se dá em contexto formal de comunicação, há, como aponta a matéria, problemas de CV, de acordo com a norma-padrão, na fala da apresentadora. Como vimos, o mesmo acontece com o Slam, mas em contextos menos monitorados e mais informais. Por que você acha que ela foi duramente criticada?

Justificativa: A questão 5 fala sobre o poema ser um gênero mais monitorado e questiona se, para os alunos, a poeta monitorou sua linguagem e se, ao monitorá-la ou não, agiu de forma estratégica. Em se tratando do gênero apresentado na questão 6 , uma matéria de um site conhecido a respeito de uma apresentadora de jornal em uma emissora de TV aberta - este se trata de um gênero mais monitorado e que se dá em contextos mais formais (aqui nos referimos tanto à matéria quanto ao contexto de apresentação do jornal) - . No entanto, como aponta a matéria, a apresentadora cometeu "erros gramaticais", o que nos leva ao fato de que a ausência da CV não acontece só em contextos menos monitorados. Essa questão mobiliza principalmente o primeiro e o terceiro eixo porque leva o aluno a refletir sobre a língua utilizada na matéria e sobre a variação linguística.

\section{Questão 7:}


Agora que você sabe mais sobre o Poetry Slam, você acredita que o fato de o poema não estar escrito de acordo com a norma-padrão está relacionado com o gênero? Justifique.

Justificativa: Acreditamos que a questão 7 também mobiliza os três eixos, o que se dá, primeiramente, porque os alunos são levados a refletirem sobre os contextos desfavorecedores de concordância. Em segundo lugar, quanto ao Eixo 2, os alunos são levados também a refletirem sobre a produção de sentidos em função de gêneros variados. E, no que tange ao Eixo 3 especificamente, são levados a pensar sobre a não utilização do padrão em função do gênero utilizado.

\section{Questão 8:}

Você acha que se colocasse os versos de acordo com a norma-padrão no poema, o efeito de sentido seria o mesmo? Por quê?

Justificativa: A questão 8 mobiliza especificamente os Eixos 1 e 2 porque leva os alunos a refletirem acerca da língua e os efeitos de sentido possíveis e variáveis de acordo com o contexto de produção do poema. $\mathrm{O}$ Eixo 2 é mobilizado também porque os alunos precisam pensar na CV no âmbito local (no texto) e, devido aos efeitos de sentido que ela causa, são levados a pensar no plano discursivo, para além do texto.

\section{Questão 9:}

Normalmente você faz uso da concordância verbal de acordo com a normapadrão? Se você fosse escrever um poema para uma batalha de Poetry Slam, você seguiria a norma-padrão ou não? E se fosse escrever um poema para entregar à professora?

Justificativa: A penúltima questão é importante porque esperamos que, ao chegar nela, os alunos tenham feito, no decorrer da atividade, uma reflexão sobre a linguagem utilizada no poema, procurado dar sentido ao gênero e ao modo como a $\mathrm{CV}$ aparece a partir do gênero específico, dentre outras reflexões e conclusões. Nessa questão 9, espera-se que os alunos mobilizem os três eixos ao refletirem sobre a linguagem que foi utilizada no poema e a que eles utilizam a depender do contexto, o sentido dado ao uso ou ao não uso da $\mathrm{CV}$ de acordo com as normas gramaticais e as variações linguísticas possíveis (tanto as que ele domina quanto as que ele não domina).

\section{Questão 10:}

Escreva um poema utilizando ou não a marcação da concordância verbal a depender do seu objetivo. Sinta-se livre quanto ao tema a ser escolhido para a sua escrita.

Justificativa: A décima e última questão é importante tanto para o aluno, porque demanda que ele mobilize os 3 eixos não apenas com o objetivo de responder à questão, mas também de produzir um texto 
artístico, quanto para o professor, que poderá ver não apenas os três eixos sendo mobilizados como em movimento durante o processo criativo (consideramos, com isso, que provavelmente essa questão seja a que demandará mais tempo e trabalho por parte dos alunos). O Eixo 1 é mobilizado tanto no que tange à natureza linguística quanto às naturezas epilinguísticas e metalinguísticas, isso porque o aluno lança mão do saber que ele já tem, opera sobre a linguagem e sistematiza-a para produzir seu próprio poema. O Eixo 2 se estabelece através do uso que os alunos farão (ou não, a depender da escolha que fizerem) da CV de modo consciente, e não mais sistematizado ou sem concordância de acordo com as normas gramaticais (o que vai depender das escolhas que farão). Por fim, o terceiro eixo é mobilizado porque terão que considerar a heterogeneidade linguística para produzirem um texto em um determinado gênero, utilizando de uma variedade linguística adequada para o gênero em questão.

\section{Considerações finais}

A introdução feita acerca da sociolinguística foi fundamental para que o nosso trabalho fosse contextualizado dentro dessa grande área. Iniciar com o que as gramáticas escolhidas têm a dizer sobre o fenômeno da concordância também nos deu base teórica para nossa reflexão. Quanto ao LD, acreditamos que reflexões a respeito desse tipo de material são interessantes porque são importantes e fazem parte do processo de aprendizagem dos alunos no ensino básico. Como a atividade proposta não foi aplicada, se trata apenas de uma proposta elaborada para conjugar o gênero escolhido com o fenômeno gramatical em questão, com base nas atividades presentes no LD "Português Linguagens" de Cereja e Magalhães (2005; 2016). Sendo assim, os resultados da atividade não são integrais, mas, sim, esperados.

Tanto com relação ao LD brevemente analisado quanto com relação ao gênero escolhido e a atividade proposta, há ainda muito a dizer. No entanto, por uma questão de espaço e para não fugirmos dos objetivos propostos, nos contentamos com o que conseguimos apresentar. Acreditamos que os nossos objetivos centrais de refletir a respeito do tratamento dado ao tema da $\mathrm{CV}$, suas variações e problematizações (tanto na sociedade quanto no LD) e a proposta de atividade com base nos três eixos, propostos por Vieira (2018), tenham sido alcançados. Perpassamos, para tanto, desde o que dizem 
as gramáticas de Bechara (2009) e Perini (2010) até chegarmos a uma proposta de atividade autoral que nos suscitou muitas outras possibilidades de trabalho com o tema, que ficarão, quem sabe, para discussões futuras.

\section{Referências}

BAGNO, M. Gramática pedagógica do português brasileiro. São Paulo: Parábola Editorial, 2012.

BAGNO, M. Não é errado falar assim! em defesa do português brasileiro. São Paulo: Parábola Editorial, 2009.

BAGNO, M. Dicionário crítico de sociolinguística. São Paulo: Parábola Editorial, 2017.

BECHARA, E. Moderna gramática portuguesa. 37. ed. revista e ampliada. Rio de Janeiro: Lucerna, 2009.

BORTONI-RICARDO, S. M. et al. Por que a escola não ensina gramática assim?. São Paulo: Parábola Editorial, 2014.

BORTONI-RICARDO, S. M. O Português brasileiro. In: BORTONI-RICARDO, S. M. Educação em língua materna: a sociolinguística na sala de aula. São Paulo: Parábola Editorial, 2004. p. 51-70.

BORTONI-RICARDO, S. M. Um modelo para a análise sociolingüística do português brasileiro. In: BORTONI-RICARDO, S.. Nós cheguemu na escola, e agora? Sociolinguística e Educação. São Paulo: Parábola Editorial, 2005. p. 45-52.

CASTRO, Daniel. Nervosismo de Maju Coutinho no Jornal Hoje acende alerta na Globo. 2019. Disponível em: https://bit.ly/3yRELGo. Acesso em: 14 ago. 2021.

CEREJA, W. R.; MAGALHÃES, T. C. Português: Linguagens. 11. ed. São Paulo: Saraiva, v. 3, 2016. Disponível em: https://bit.ly/3CRXcwq. Acesso em: 18 ago. 2020.

CEREJA, W. R.; MAGALHÃES, T. C. Português: Linguagens. 5. ed. São Paulo: Atual, v. 3, 2005. 
CHAGAS, D. S. Concordância verbal de terceira pessoa: descrição sociolinguística e proposta pedagógica em turmas do ensino fundamental. 2016. 201 p. Dissertação (Mestrado em Letras) - Universidade Federal do Rio de Janeiro, Rio de Janeiro, 2016.

CHAGAS, D. S. Concordância verbal: estratégias para o trabalho com os três eixos para o ensino de gramática. In: VIEIRA, S. R. (Org.). Gramática, variação e ensino: diagnose e propostas pedagógicas. São Paulo: Blucher, 2018. p. 61-94.

FARACO, C. A. Norma culta brasileira: desatando alguns nós. São Paulo: Parábola Editorial, 2008.

FARACO, C. A; ZILLES, A. M. Norma e ensino. In: FARACO, C. A; ZILLES, A. M. (Org.). Para conhecer norma linguística. São Paulo: Contexto, 2017, p. 173-207.

GÖRSKI, E. M.; FREITAG, R. M. K. O papel da Sociolinguística na formação dos professores de língua portuguesa como língua materna. In: MARTINS, M. A.; TAVARES, M. A. (Org.). Contribuições da Sociolinguística e da Linguística Histórica para o ensino de língua portuguesa. Coleção Ciências da Linguagem Aplicadas ao Ensino. Natal: EDUFRN, volume V, 2013. p. 11-50.

LABOV, W. Padrões sociolinguísticos. São Paulo: Parábola, 2008.

MOLLICA, M. C. Fundamentação teórica: conceituação e delimitação. In: MOLLICA, M.

C; BRAGA, M. L. (Orgs.). Introdução à sociolinguística: o tratamento da variação. São Paulo: Contexto, 2003. p. 9-14.

PERINI, M. Gramática do português brasileiro. São Paulo: Parábola Editorial, 2010.

RAMOS, Heloísa. (Org.) Por uma vida melhor: Educação de Jovens e Adultos: segundo seguimento do ensino fundamental, vol. 2. São Paulo: Global: Ação Educativa, 2011. (Coleção Viver e Aprender).

RISSATO, C. B. Variação linguística e ensino: o fenômeno da concordância verbal no sexto ano do ensino fundamental II de uma escola pública de Orlândia-SP. 2018. 154 p. Dissertação (Mestrado em Letras) - Universidade Federal do Triângulo Mineiro, Uberaba, 2018. 
SOCIEDADE DOS POETAS SUBVERSIVOS. Menimelimentros. Disponível em: $<$ https://www.youtube.com/watch?v=wcli4M-WcYg>. Acesso em: 24 mar. 2020.

VIEIRA, S. R.; BRANDÃO, S. F. Ensino de gramática descrição e uso. São Paulo: Contexto, 2014.

VIEIRA, S. R. Três eixos para o ensino de gramática. In: VIEIRA, S. R (Org.). Gramática, variação e ensino: diagnose e propostas pedagógicas. Rio de Janeiro: Letras UFRJ, 2018. p. 47-58.

Recebido em 23/o1/2021. Aprovado em 27/o8/2021. 


\section{APÊNDICE}

PLANO DE AULA

Tema: Concordância verbal

Público alvo: alunos da $3^{a}$ série do ensino médio

- Objetivos gerais:

- Levar o aluno a refletir acerca do fenômeno da concordância verbal a partir do gênero Poetry Slam.

- Objetivos específicos:

- Apresentar o Poetry Slam;

- Ampliar a discussão acerca do tema proposto (concordância verbal);

- Levar o aluno a refletir acerca da língua em uso em contextos menos monitorados e em contextos mais monitorados;

- Promover o acesso do aluno às variedades linguísticas mais prestigiosas através do uso adequado do fenômeno da concordância verbal.

- Conteúdo programático:

- Apresentar o gênero Poetry Slam aos alunos;

- Iniciar uma discussão acerca do gênero e sua relação com a linguagem;

- Apresentar o tema da concordância verbal;

- Aplicar a atividade sempre propondo a reflexão por parte dos alunos tanto em relação ao gênero quanto ao tema;

- Aferir, desde o início da apresentação até a execução da atividade, a familiaridade ou não do tema por parte dos alunos.

Materiais: Projetor, lousa, caneta/giz, papel, caneta.

Recursos didáticos: recursos de mídia e xerox.

Tempo de aula: três aulas de 45 minutos cada. 